\title{
Thermocline mixing and vertical oxygen fluxes in the stratified central North Sea
}

\author{
Lorenzo Rovelli $^{1,2, a}$, Marcus Dengler ${ }^{1}$, Mark Schmidt ${ }^{1}$, Stefan Sommer $^{1}$, Peter Linke ${ }^{1}$, and Daniel F. McGinnis ${ }^{1,3}$ \\ ${ }^{1}$ GEOMAR Helmholtz Centre for Ocean Research Kiel, Kiel, Germany \\ ${ }^{2}$ Scottish Association for Marine Sciences (SAMS), Oban, UK \\ ${ }^{3}$ Institute F.-A. Forel, Faculty of Science, University of Geneva, Geneva, Switzerland \\ a now at: Nordic Center for Earth Evolution (NordCEE), Department of Biology, University of Southern Denmark, Odense, \\ Denmark
}

Correspondence to: Lorenzo Rovelli (lorenzo@biology.sdu.dk)

Received: 24 April 2015 - Published in Biogeosciences Discuss.: 3 July 2015

Revised: 8 February 2016 - Accepted: 26 February 2016 - Published: 15 March 2016

\begin{abstract}
In recent decades, the central North Sea has been experiencing a general trend of decreasing dissolved oxygen $\left(\mathrm{O}_{2}\right)$ levels during summer. To understand potential causes driving lower $\mathrm{O}_{2}$, we investigated a 3-day period of summertime turbulence and $\mathrm{O}_{2}$ dynamics in the thermocline and bottom boundary layer (BBL). The study focuses on coupling biogeochemical with physical transport processes to identify key drivers of the $\mathrm{O}_{2}$ and organic carbon turnover within the BBL. Combining our flux observations with an analytical process-oriented approach, we resolve drivers that ultimately contribute to determining the $\mathrm{BBL} \mathrm{O}_{2}$ levels. We report substantial turbulent $\mathrm{O}_{2}$ fluxes from the thermocline into the otherwise isolated bottom water attributed to the presence of a baroclinic near-inertial wave. This contribution to the local bottom water $\mathrm{O}_{2}$ and carbon budgets has been largely overlooked and is shown to play a role in promoting high carbon turnover in the bottom water while simultaneously maintaining high $\mathrm{O}_{2}$ concentrations. This process may become suppressed with warming climate and stronger stratification, conditions which could promote migrating algal species that potentially shift the $\mathrm{O}_{2}$ production zone higher up within the thermocline.
\end{abstract}

\section{Introduction}

\subsection{Hypoxia in shelf seas and coastal regions}

The distribution of dissolved oxygen $\left(\mathrm{O}_{2}\right)$ in marine systems results from a complex interaction between biological processes (photosynthesis and respiration) and physical processes $\left(\mathrm{O}_{2}\right.$ flux pathways) occurring within the water column and at the seafloor. $\mathrm{O}_{2}$ is regarded as an important indicator of ecosystem functioning for aquatic organisms (Best et al., 2007) and for benthic activity (e.g., Glud, 2008). Changes in $\mathrm{O}_{2}$ distribution, concentrations and supply can therefore have severe impacts on shelf ecosystems. $\mathrm{O}_{2}$ concentrations below $62.5 \mu \mathrm{mol} \mathrm{L}{ }^{-1}$, which is generally regarded as the threshold of hypoxia (Vaquer-Sunyer and Duarte, 2008), are shown to significantly stress aquatic communities and increase the mortality among fish communities (Diaz, 2001). These ecological and economic impacts of $\mathrm{O}_{2}$ depletion lead to increasing concern regarding hypoxia occurrence and hypoxic events. As reviewed by Diaz and Rosenberg (2008), hypoxia in coastal environments is spreading and so are the reports of unprecedented occurrence of hypoxia in several shelf seas and coastal regions (Grantham et al., 2004; Chan et al., 2008; Crawford and Pena, 2013).

\subsection{Hydrodynamics and oxygen depletion in the North Sea}

The North Sea is situated on the northwest European continental shelf, between the British Islands and continental Europe (Fig. 1). Its semi-enclosed basin covers an area of $575300 \mathrm{~km}^{2}$, with an average depth of $74 \mathrm{~m}$ and a general decrease in depth from north to south (Otto et al., 1990). The central region is characterized by the presence of the Dogger Bank, a shallow sandbank that acts as a hydrological divide. The northern and central North Sea hydrology is mainly 


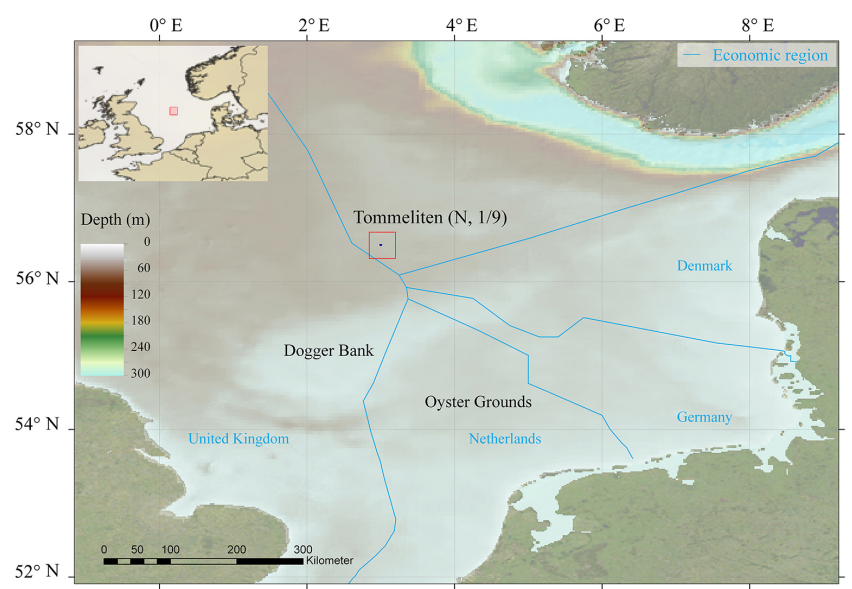

Figure 1. Map of the North Sea indicating the water depths and location of the Tommeliten site and the borders of the economic regions of the surrounding European countries.

dominated by inflow from the North Atlantic Ocean at the northern open boundary, while the southern part relies on inflow from the English Channel (Thomas et al., 2005). Northern and central North Sea areas are characterized by seasonal water column stratification (from April to SeptemberOctober; Meyer et al., 2011). With only weak, wind-driven residual currents (Otto et al., 1990), this stratification leads to isolation of central North Sea bottom water and subsequent $\mathrm{O}_{2}$ depletion.

In the central North Sea, the occurrence of low $\mathrm{O}_{2}$ levels in bottom waters has been reported (e.g., North Sea Task Force, 1993; Greenwood et al., 2010). Additional monitoring studies in the central North Sea in 2007 and 2008 have shown that $\mathrm{O}_{2}$ concentration in bottom waters at the Oyster Grounds and North Dogger can drop to $163-169 \mu \mathrm{mol} \mathrm{L}^{-1}$ (60-63\% saturation) and $\sim 200 \mu \mathrm{mol} \mathrm{L}^{-1}$ (71\% saturation), respectively (Fig. 1; Greenwood et al., 2010). Comparable field observations were also reported in the summer of 2010 (Queste et al., 2013). The authors also reviewed the available historical $\mathrm{O}_{2}$ data in the North Sea (1900-2010), revealing a clear increase in $\mathrm{O}_{2}$ depletion after 1990.

While the reported $\mathrm{O}_{2}$ levels were still above the hypoxic threshold, growing concerns of hypoxia developing in the North Sea have highlighted the need for more detailed studies on $\mathrm{O}_{2}$ dynamics and its driving forces (Kemp et al., 2009). Since 1984, surface water temperatures in the North Sea have increased by $1-2{ }^{\circ} \mathrm{C}$ higher than the global mean (OSPAR, 2009, 2010; Meyer et al., 2011). On seasonal timescales, climate projections indicate longer durations of the stratification period and stronger thermocline stability (Lowe et al., 2009; Meire et al., 2013), with some projections suggesting earlier onset of stratification (e.g., Lowe et al., 2009). Due to the semi-enclosed nature of the North Sea, earlier onset and longer stratification increases the length of time that deep waters are isolated, potentially allowing lower $\mathrm{O}_{2}$ concentrations to develop (Greenwood et al., 2010).

\subsection{Physical drivers of oxygen dynamics}

The distribution of $\mathrm{O}_{2}$ and other dissolved constituents within aquatic systems are largely driven by physical transport processes. These include wind-driven air-water-gas exchange at the sea surface (Wanninkhof, 1992), molecular diffusion at the sediment-water interface (Jørgensen and Revsbech, 1985), horizontal advection (e.g., Radach and Lenhart, 1995) and turbulent transport in the water column, where the latter transport was reported to significantly contribute to constituent balances (see Rippeth, 2005; Fischer et al., 2013; Kreling et al., 2014; Brandt et al., 2015). In shelf seas, the seasonal occurrence of steep thermoclines acts as an important physical barrier separating the surface layer from nutrient-rich deeper waters (Sharples et al., 2001). As measurements of shear and stratification have shown, the central North Sea thermocline is in a state of marginal stability (van Haren et al., 1999). Hence additional sources of shear could trigger shear instability leading to local production of turbulence within the thermocline. This enhanced local turbulence would subsequently enhance the vertical exchange of constituents such as $\mathrm{O}_{2}$, organic carbon and nutrients. Resolving processes that drive diapycnal (i.e., vertical) fluxes across the thermocline throughout the stratification period is key to understanding the biogeochemical functioning of shelf seas (e.g., Sharples et al., 2001).

\subsection{Present study}

The goal of this study is to provide understanding of key turbulent processes driving $\mathrm{O}_{2}$ fluxes across the thermocline during the summertime stratification period in the central North Sea using data from a 3-day process study. We investigate and describe $\mathrm{O}_{2}$ dynamics and fluxes to the bottom waters and discuss their potential influence on the seasonal $\mathrm{O}_{2}$ balance. Using the resolved $\mathrm{O}_{2}$ fluxes, we perform a simple 1-D mass balance model to quantify $\mathrm{O}_{2}$ sources and sinks. Finally, processes that could further promote hypoxia in the central North Sea in a warming climate are discussed.

\section{Methods}

\subsection{Study site}

We performed $\mathrm{O}_{2}$ and turbulence measurements in the Norwegian sector of the central North Sea, N. 1/9, at the Tommeliten site $\left(56^{\circ} 29^{\prime} 30^{\prime \prime} \mathrm{N}, 2^{\circ} 59^{\prime} 00^{\prime \prime} \mathrm{E}\right.$; Fig. 1) from 8-11 August 2009 aboard the R/V Celtic Explorer (cruise CE0913). The site, located $\sim 100 \mathrm{~km}$ northeast from the northern Dogger Bank, and its surroundings are characterized by shallow waters $(\sim 70 \mathrm{~m})$ relatively far from coastal areas (on average $\sim 3000 \mathrm{~km}$ ). The site is known for the presence of buried salt 
diapirs, methane $\left(\mathrm{CH}_{4}\right)$ seeps and bacterial mats (Hovland and Judd, 1988). Bathymetric surveys from Schneider von Deimling et al. (2010) revealed a rather flat sandy seabed with almost no features, with the exception of centimetersized ripples (McGinnis et al., 2014).

The currents of the central North Sea are predominantly driven by the semi-diurnal lunar tide $\left(M_{2}\right)$ (Otto et al., 1990). Seasonal stratification begins in April around Julian day 100 and lasts until the end of September or early October, Julian days 270-290 (e.g., Meyer et al., 2011). The thermocline has been identified as an important zone for the establishment of primary production and the $\mathrm{O}_{2}$ maximum layer (see Pingree et al., 1978). In fact, the North Sea deep chlorophyll maximum (DCM) is estimated to account for $58 \%$ of the water column primary production and $37 \%$ of the annual new production for the summer stratified North Sea (Weston et al., 2005). Thus, the development of the associated $\mathrm{O}_{2}$ maximum due to this production is important and, so far, not considered in the overall $\mathrm{O}_{2}$ balance of the central North Sea.

\subsection{Instrumental setup}

High-resolution (millimeter-scale) turbulent shear and temperature profiles were obtained with a MSS90-L microstructure turbulence profiler (Sea and Sun Technology, Trappenkamp, Germany). The MSS90-L is a free-falling, loosely tethered profiler which samples at $1024 \mathrm{~Hz}$ with 16 channels and is designed for an optimal sink rate of $0.5-0.6 \mathrm{~m} \mathrm{~s}^{-1}$. The probe was equipped with two airfoil shear probes, an accelerometer (to correct for probe pitch, roll and vibration), a fast temperature sensor (FP07, 7-12 ms response time), standard CTD sensors (temperature, pressure, conductivity) and a fast ( $0.2 \mathrm{~s}$ response time) galvanic $\mathrm{O}_{2}$ sensor (AMT, Analysenmesstechnik $\mathrm{GmbH}$, Rostock, Germany). Absolute $\mathrm{O}_{2}$ concentrations were calibrated against shipboard CTD $\mathrm{O}_{2}$ profiles and Winkler titrations using discrete water samples (see below).

Water column hydrodynamics were characterized with the compact benthic paleoceanography (POZ) lander, which was deployed using a video-guided launcher (Pfannkuche and Linke, 2003). The POZ lander recorded 3-D current velocity profiles and acoustic backscatter information throughout the water column using a $300 \mathrm{kHz}$ acoustic Doppler current profiler (ADCP; Workhorse Sentinel, Teledyne RD Instruments, Poway, United States), which sampled every $15 \mathrm{~s}$ with a bin size of $0.5 \mathrm{~m}$ starting from $2.75 \mathrm{~m}$ from the bottom. A conductivity-temperature-depth (CTD) logger (XR420 CT logger, RBR, Canada) recorded temperature, conductivity and pressure (Digiquartz, Paroscientific, Redmond, United States) every $2 \mathrm{~s}$ near the seafloor $(\sim 0.3 \mathrm{~m}$ distance $)$. The POZ lander was also equipped with a Winkler-calibrated $\mathrm{O}_{2}$ optode sensor (Aanderaa Data Instruments AS, Bergen, Norway), which recorded bottom boundary layer (BBL) $\mathrm{O}_{2}$ concentration at 1 min intervals.
Water column profiles were obtained using a SBE9plus CTD-rosette system (Seabird, Washington, United States). The CTD sampled at $24 \mathrm{~Hz}$ and was equipped with standard temperature, conductivity, pressure, $\mathrm{O}_{2}$ and light transmission sensors. The rosette system mounted 12 Niskin bottles $(10 \mathrm{~L}$ each) for discrete water sampling. Each water sample was subsampled with three Winkler bottles of known volume ( $\sim 62 \mathrm{~mL}$ on average) upon recovery, and the samples were immediately fixed on deck and titrated manually within $24 \mathrm{~h}$ after the sampling (see Winkler, 1888). CTD $\mathrm{O}_{2}$ readings were calibrated against $\mathrm{O}_{2}$ concentrations from Winkler samples; values deviated by $<5 \%$.

\subsection{Hydrodynamic data evaluation}

The main tidal directions (major and minor axis of the tidal ellipsoid) were determined by performing a variance analysis on the ADCP velocity time series. The $u$ and $v$ velocities were rotated over a stepwise increasing rotation angle $(r)$ as $u_{\text {rot }}=u \cos (-r)-v \sin (-r)$ and $v_{\text {rot }}=u \sin (-r)+$ $v \cos (-r)$, and the variance was computed at each step. The angle with the largest variance is the main tidal direction. Barotropic and baroclinic flow contributions of tides were separated by least-square fitting the detrended velocity time series to harmonics $u=A \cos (\omega t+\varphi)$ with $A, \omega, \phi$ being the amplitude, frequency, and the phase lag, respectively. In the analysis below, the barotropic semi-diurnal principle lunar tide $\left(M_{2}\right)$ and diurnal declination tide $\left(K_{1}\right)$ contributions had frequencies of 1.93227 cycles per day (cpd) and $1.00274 \mathrm{cpd}$, respectively, and were subtracted from the time series to analyze residual flow. For barotropic contributions, the fit was applied to the depth average of the time series, while baroclinic contributions were obtained by fitting the harmonics to the velocity time series from each $0.5 \mathrm{~m}$ ADCP bin. The occurrence of enhanced shear in the stratified water column was investigated by calculating the vertical shear of horizontal velocity, $S$, from the vertical gradients between adjacent bins of east and north velocity $(0.5 \mathrm{~m}$ resolution) as $S=\sqrt{(\mathrm{d} u / \mathrm{d} z)^{2}+(\mathrm{d} v / \mathrm{d} z)^{2}}$. Frequency spectra of the time series of horizontal velocity and vertical shear of horizontal velocity were used to identify the tidal and non-tidal flow components. The spectra were calculated using fast Fourier transforms combined with a $1 / 2$ cosine taper (Hanning window), which was applied to the first and last $10 \%$ of the time series data.

Turbulent kinetic energy dissipation rate $(\varepsilon)$ was quantified from airfoil shear readings by integrating shear wavenumber spectra assuming isotropic turbulence (Batchelor, 1953):

$\varepsilon=7.5 \mu \int_{k_{\min }}^{k_{\max }} E_{\mathrm{d} u^{\prime} / \mathrm{d} z}(k) \mathrm{d} k$,

where $\mu$ is the dynamic viscosity of seawater. Shear spectra $E_{\mathrm{d} u^{\prime} / \mathrm{d} z}(k)$ were calculated from $1 \mathrm{~s}$ ensembles (1024 values) and integrated between a lower $k_{\min }=3$ cycles per minute (cpm) and an upper wavenumber $k_{\min }$ that varied between 
14 and $30 \mathrm{cpm}$ depending on the Kolmogorov wavenumber. Here, a Bartlett window was applied to the whole ensemble prior to spectral decomposition. Loss of variance due to limited wavenumber band was taken into account by fitting the observed shear spectra to the universal Nasmyth spectrum. Similarly, corrections for the loss of variance due to finite sensor tip of the airfoil probes were applied (see Schafstall et al., 2010). The detection limit, or noise level, of the used profiler for $\varepsilon$ was inferred to be $1 \times 10^{-9} \mathrm{~W} \mathrm{~kg}^{-1}$ (Schafstall et al., 2010); the upper detection limit is a function of the shear sensor geometry (up to $10^{-4} \mathrm{~W} \mathrm{~kg}^{-1}$; Prandke and Stips, 1998).

Estimates of turbulent eddy diffusivities of mass $\left(K_{\rho}\right)$ were obtained from measurements of $\varepsilon$ as

$K_{\rho}=\gamma \varepsilon / N^{2}$,

where $\gamma$ is the mixing efficiency and $N^{2}$ the water column stability. This method, proposed by Osborn (1980), approximates $K_{\rho}$ under the assumption of a local equilibrium of production and dissipation of turbulent kinetic energy. Values for $N^{2}$ were calculated from temperature, salinity and pressure data using the adiabatic method (Fofonoff, 1985) as $N^{2}=$ $-\mathrm{g}\left(\rho^{-1} \partial \rho / \partial z-g / c^{2}\right)$, where $\rho, g$, and $c$ are the density, the earth's gravitational acceleration, and speed of sound. Mixing efficiency values in stratified waters range from 0.1 to 0.2 (Ivey and Imberger, 1991) and decrease in weakly stratified waters such as within the BBL (Lorke et al., 2008). To account for this decrease, we used the $\gamma$ and $K_{\rho}$ parameterization of Shih et al. (2005). Based on the turbulence activity parameter $\varepsilon / v N^{2}$, with the kinematic viscosity, $v$, the authors found that in energetic regimes, i.e., $\varepsilon / v N^{2}>100$, eddy diffusivities are better estimated as $K_{\rho}=2 v\left(\epsilon / v N^{2}\right)^{1 / 2}$. As horizontal density gradients at the study site were deemed to be small compared to vertical gradients (see Discussion), we equated diapycnal eddy diffusivities with vertical diffusivities (i.e., $K_{\rho}=K_{z}$ ).

To obtain representative mean turbulent eddy diffusivities, the data were evaluated in ensembles of three to four consecutive profiles and averaged in depth and time to reduce uncertainties due to the patchiness of turbulence, temporal fluctuation of $N^{2}$ and temporal $\gamma$ variations (see Smyth et al., 2001). As proposed by Ferrari and Polzin (2005), the level of uncertainty of the averaged $K_{z}$ can be quantified as:

$\Delta K_{z}=K_{z}\left[\left(\frac{\Delta \gamma}{\gamma}\right)^{2}+\left(\frac{\Delta \varepsilon}{\varepsilon}\right)^{2}+\left(\frac{\Delta N^{2}}{N^{2}}\right)^{2}\right]^{1 / 2}$,

with $\Delta$ being the absolute uncertainty of the various average terms. Here, the uncertainties are evaluated in the region of strong vertical $\mathrm{O}_{2}$ gradients and in $2 \mathrm{~m}$ depth bins. The absolute uncertainty for $\Delta \gamma$ was assumed to be 0.04 (see St. Laurent and Schmitt, 1999). The absolute uncertainty on $N^{2}$ $\left(\Delta N^{2}\right)$ was determined by the standard error over the $2 \mathrm{~m}$ average, computed as the standard deviation divided by the square root of the number of estimates. Finally, the statistical uncertainty of $\varepsilon$ for each bin was calculated using a bootstrap method ( $10^{4}$ resamples) (Efron, 1979).

The vertical $\mathrm{O}_{2}$ fluxes $F_{\theta}$ were then obtained from $K_{z}$ and the $\mathrm{O}_{2}$ concentration gradients $\partial\left[\mathrm{O}_{2}\right] / \partial z$ as

$F_{\theta}=K_{z} \frac{\partial\left[\mathrm{O}_{2}\right]}{\partial z}$.

Accordingly, the uncertainty of averaged turbulent $\mathrm{O}_{2}$ fluxes were given by

$\Delta F_{\theta}=F_{\theta}\left[\left(\frac{\Delta K_{z}}{K_{z}}\right)^{2}+\left(\frac{\Delta \partial_{z}\left[\mathrm{O}_{2}\right]}{\partial_{z}\left[\mathrm{O}_{2}\right]}\right)^{2}\right]^{1 / 2}$,

where $\Delta \partial_{z}\left[\mathrm{O}_{2}\right]$ denotes the standard error of mean vertical gradients of $\mathrm{O}_{2}$ concentrations. It should be noted that the analysis did not include biases or uncertainties due to measurement errors.

\section{Results}

During the 3-day observational period (8-11 August 2009), we collected 39 high-resolution MSS profiles in consecutive sets of three to five profiles at 5-10 min intervals. Most of the profiles were in the evening (profiles 1-8, 26-28, 36-39) or at night $(9-15,29-35)$ with the remaining profiles acquired in the morning (06:00 to 09:00). One shipboard CTD profile was performed prior to the actual MSS profiles to provide hydrographic information, the water turbidity and $\mathrm{O}_{2}$ concentrations, and discrete water samples for subsequent onboard Winkler titrations. Hydroacoustic water column current measurements were carried out continuously throughout the observational period. The following results are structured to first present a characterization of the site's physical settings and turbulence drivers, followed by the $\mathrm{O}_{2}$ fluxes and $\mathrm{O}_{2}$ BBL budget.

\subsection{Water column structure}

The $\sim 70 \mathrm{~m}$ deep water column was characterized by a stable, well-defined four-layer temperature structure (Fig. 2a). The well-mixed surface boundary layer (SBL) and BBL, 15 and $30 \mathrm{~m}$ thick, respectively, were separated by a weakly stratified transition layer (15-25 $\mathrm{m}$ depth) and a strongly stratified interior layer (25-40 m depth). The stratified interior layer was characterized by two very steep thermoclines situated in the upper (27-30 $\mathrm{m}$ depth) and lower (36-39 $\mathrm{m}$ depth) region of the layer, with vertical temperature gradients of up to $4{ }^{\circ} \mathrm{C} \mathrm{m}^{-1}$. The average salinity was 35.08 with little variation throughout the water column (35.04-35.1). The light transmission profile from the ship CTD ranged from 89 to $96 \%$ (Fig. 2b). The most turbid layer (89\%) was observed at the lower boundary of the interior layer (at $40 \mathrm{~m}$ depth) suggesting the presence of the deep chlorophyll maximum, phytoplankton, zooplankton and suspended particles. 


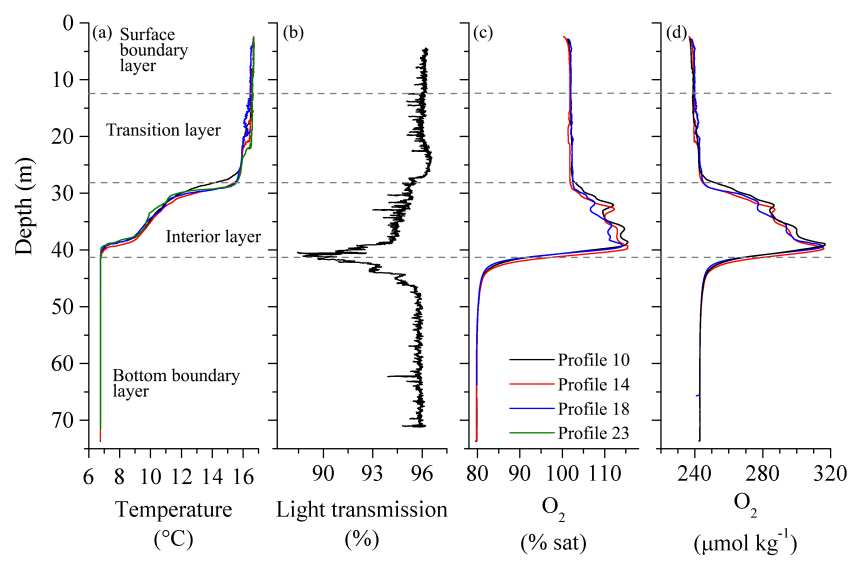

Figure 2. Water column profiles based on high-resolution MSS profiles (a, c, d) and ship CTD profile (b). (a) Potential temperature profiles. Water column layers were identified based on the temperature profiles. A 0.2 and $1.5^{\circ} \mathrm{C}$ decrease from the surface boundary layer average temperature (3-6 $\mathrm{m}$ depth) was used determine the depth of the surface boundary layer to the transition layer interface and the transition layer to the interior layer interface, respectively. Correspondingly, a $0.2^{\circ} \mathrm{C}$ from a $50-60 \mathrm{~m}$ depth average temperature was used to locate the interior layer to the BBL interface. (b) Light transmission profile. (c, d) $\mathrm{O}_{2}$ saturation profiles and associated absolute concentrations.

The $\mathrm{O}_{2}$ profiles were generally characterized by near saturation in the SBL and transition layers $\left(238-243 \mu \mathrm{mol} \mathrm{kg}^{-1}\right)$ and undersaturated $(\sim 80 \%)$ in the BBL $\left(\sim 243 \mu \mathrm{mol} \mathrm{kg}^{-1}\right)$ (Fig. 2c, d). The stratified interior layer was oversaturated by up to $115 \%$, with a well-established $\mathrm{O}_{2}$ maximum at $\sim 39 \mathrm{~m}$ depth with concentrations up to $\sim 315 \mu \mathrm{mol} \mathrm{kg}{ }^{-1}$. Below that maximum, at the thermocline-BBL interface, we observed a 2-3 $\mathrm{m}$ thick steep oxycline, with an $\mathrm{O}_{2}$ gradient of $34 \mu \mathrm{mol} \mathrm{kg}{ }^{-1} \mathrm{~m}^{-1}$. We did not detect significant variations in the $\mathrm{O}_{2}$ values, or gradient over our limited measurement range (Fig. 2c, d). We resolve the $\mathrm{O}_{2}$ flux into the BBL associated with this oxycline.

\subsection{Hydrodynamics}

The hydrostatic pressure data set (POZ lander) revealed that the tidal water level ranged from 0.6 to $0.9 \mathrm{~m}$ (Fig. 3a). Variance analysis on the ADCP velocity data identified the major and minor axis of the tidal ellipsoid components to occur at 45 and $135^{\circ}$ from true north, respectively. Along these axes, the current amplitudes were 0.21 and $0.04 \mathrm{~m} \mathrm{~s}^{-1}$, indicating a narrow tidal current ellipsoid, as reported by Otto et al. (1990). The site was characterized by a negative tide polarity (anticyclonic) for the semi-diurnal tides. A dominance of the barotropic $M_{2}$ current amplitude at all depths was clearly visible in the velocity time series (Fig. 3b, c) and the harmonic analyses. East (zonal) and north (meridional) barotropic $M_{2}$-current amplitudes were 0.12 and $0.17 \mathrm{~m} \mathrm{~s}^{-1}$,
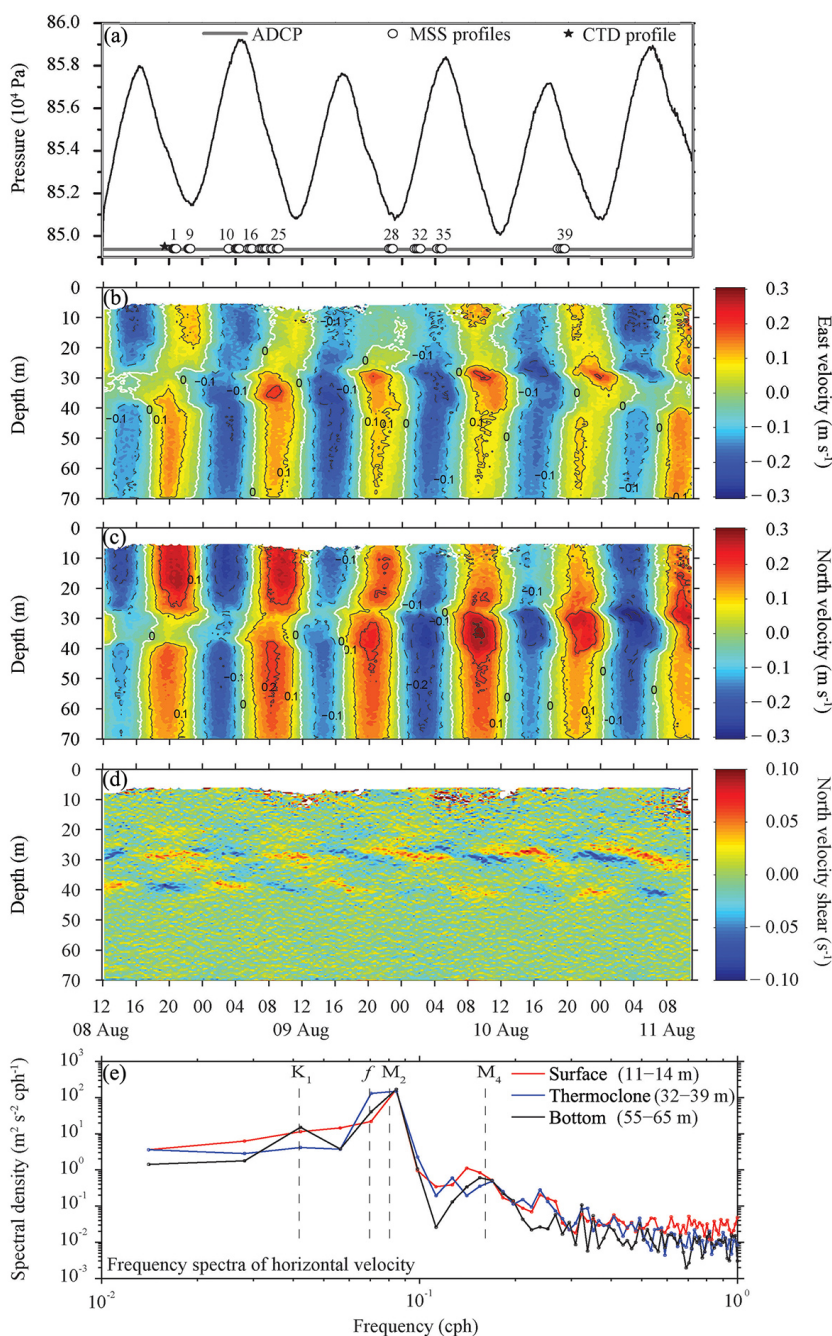

Figure 3. Current regime at the Tommeliten site from ADCP measurements (a-d) and spectral analysis (e). (a) Sea surface elevation relative to average level during the observational period (elevation $=0 \mathrm{~m}$ ) and schedule of different instrument deployments. Numbers on the MSS markers indicate the profile number. (b, c) Horizontal velocities, showing $20 \mathrm{~min}$ averaged east (b) and north (c) velocities. (d) Vertical shear of north velocity, $\mathrm{d} v / \mathrm{d} z$, calculated from the ADCP velocity data (see panels b, c). Note that panels (a-d) have the same time axis. (e) Frequency spectra of horizontal velocity calculated from the ADCP data for selected depth ranges for the SBL (surface; red line), thermocline (blue line) and BBL (bottom; black line). The inertial frequency, $f$, and the frequency for the diurnal declination tide, $K_{1}$, semi-diurnal lunar tide, $M_{2}$, and shallow water tidal constituent, $M_{4}$, are marked.

respectively, while $K_{1}$-current amplitudes were only 0.005 and $0.03 \mathrm{~m} \mathrm{~s}^{-1}$.

Although the limited length of the ADCP velocity time series did not allow for full separation of the $M_{2}$ and $f$ frequencies, the spectral density functions indicated maximum energy at frequencies of about the semi-diurnal tide. This maximum varied little with depth, indicating barotropic 
$\mathrm{M}_{2}$ motions. Superimposed on those barotropic currents, we observed the presence of baroclinic velocity contributions (Fig. 3b, c). Additionally, near-inertial motions were also detected.

The occurrence of near-inertial motions was most pronounced in the thermocline (32-39 m; Fig. 3e). Lower, but still elevated, energy densities at the near-inertial band were found in the SBL and BBL. Moreover, the near-inertial currents exhibited a distinct $180^{\circ}$ phase shift between the SBL and the thermocline as well as between the thermocline and the BBL, suggesting a second vertical mode nature of these fluctuations. Average amplitudes of the near-inertial fluctuations in the thermocline obtained from least-square fitting were $0.11 \mathrm{~m} \mathrm{~s}^{-1}$. In the BBL and SBL, average amplitudes were reduced to 0.06 and $0.04 \mathrm{~m} \mathrm{~s}^{-1}$, respectively, suggesting that $f$ oscillations might account for enhanced shear in the thermocline.

Enhanced vertical shear of horizontal velocity was found at the interior layer to the transition layer and at the interior layer to the BBL interfacial regions (Fig. 3d). As indicated by the spectral density function of the shear time series from the interior layer interfacial layers (Fig. S1 in the Supplement), the shear exhibited near-inertial frequencies $(1.6722 \mathrm{cpd})$, and resulted from the baroclinic near-inertial wave. The high vertical resolution $(0.5 \mathrm{~m})$ of our velocity data allowed the resolution of the interfacial shear layers, which were typically $2-3 \mathrm{~m}$ thick with elevated values of up to $0.05 \mathrm{~s}^{-1}$. Comparisons with CTD data showed that they are collocated with the two enhanced temperature gradient layers in the thermocline (27-30 and 36-39 m depth; Fig. 2a).

The dissipation rates $(\varepsilon)$ of turbulent kinetic energy (TKE) determined from microstructure shear probes were particularly low in the center of the stratified interior layer (2$5 \times 10^{-9} \mathrm{~W} \mathrm{~kg}^{-1}$ ) but still above the MSS detection limit. However, $\varepsilon$ increased to $5 \times 10^{-9}$ and $2 \times 10^{-8} \mathrm{~W} \mathrm{~kg}^{-1}$ at the upper and lower interior layer limits, respectively (Fig. 4a). These coincided with the depth range of the interfacial shear layers (Fig. 3d) at the strong temperature gradients (Fig. 2a) and resulting water column stability maxima $\left(\sim 1 \times 10^{-3} \mathrm{~s}^{-2}\right)$.

Bin-averaged values of $K_{z}$ varied by a factor of 5 , ranging from $6 \times 10^{-7} \mathrm{~m}^{2} \mathrm{~s}^{-1}$ in the central interior layer to $3 \times 10^{-6} \mathrm{~m}^{2} \mathrm{~s}^{-1}$ in the lower region of the transition layer (Fig. 4b). In the upper interface (thermocline-transition layer), where $\varepsilon$ was elevated with respect to the central interior layer but reduced compared to the lower interfacial layer, stronger stratification (i.e., larger $N^{2}$ values up to $10^{-3} \mathrm{~s}^{-2}$ ) reduced the eddy diffusivities. At the interior layer to the BBL interface, higher $K_{z}$ values $\left(\sim 2 \times 10^{-5} \mathrm{~m}^{2} \mathrm{~s}^{-1}\right)$ resulted from increased turbulence and weaker stratification. This enhanced turbulent transport was located where the vertical $\mathrm{O}_{2}$ gradient was the strongest (Fig. 2d).
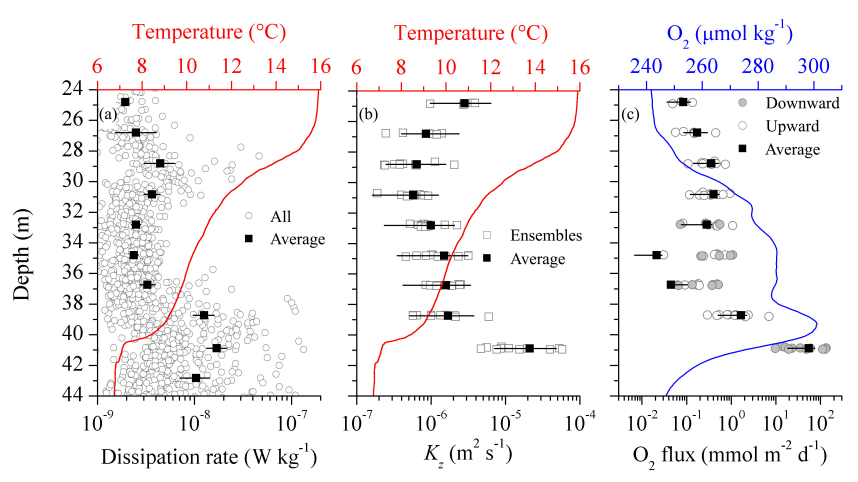

Figure 4. Overview of turbulent transport and $\mathrm{O}_{2}$ fluxes within the interior layer (defined in Fig. 2). Each panel is overlaid with temperature (a, b) and $\mathrm{O}_{2}$ concentration (c) profiles. (a) Dissipation from all profiles (open dots) together with the arithmetic mean (solid squares). (b) Average vertical eddy diffusion coefficient $K_{z}$ with uncertainties bars and the $K_{Z}$ values for every ensemble (open squares), which represent the average over 3-4 consecutive profiles. (c) Calculated average $\mathrm{O}_{2}$ flux over $2 \mathrm{~m}$ bins with the respective uncertainties intervals (solid square and black line). The values for each profile cluster are shown both downward and upward fluxes (grey solid and open dots, respectively). Note that in the center interior layer $(33-37 \mathrm{~m})$ the average reflects the combination of the variability of the observed upward and downwards fluxes.

\subsection{Oxygen fluxes and budget}

With the fast-responding AMT galvanic $\mathrm{O}_{2}$ sensor and rapid sampling rate, we were able to resolve the $\mathrm{O}_{2}$ gradient with high precision. Figure $4 \mathrm{c}$ shows the $2 \mathrm{~m}$ bin average $\mathrm{O}_{2}$ fluxes for the interior layer together with the averages from each ensemble. Small $\mathrm{O}_{2}$ fluxes $\left(\sim 1 \mathrm{mmol} \mathrm{m}^{-2} \mathrm{~d}^{-1}\right)$ were estimated for the center and upper region of the interior layer, suggesting that relatively little $\mathrm{O}_{2}$ is transported upward from the $\mathrm{O}_{2}$ maximum to the upper interior layer. In contrast, a substantial $\mathrm{O}_{2}$ flux ranging from $9-134 \mathrm{mmol} \mathrm{m}^{-2} \mathrm{~d}^{-1}$ (average of $54 \mathrm{mmol} \mathrm{m}^{-2} \mathrm{~d}^{-1}$ ) was identified from the lower thermocline towards the BBL. The confidence interval associated with the uncertainties of the $\mathrm{O}_{2}$ flux estimates was 18$74 \mathrm{mmol} \mathrm{m}^{-2} \mathrm{~d}^{-1}$. Although the $\mathrm{O}_{2}$ fluxes to the BBL water from the thermocline were variable in magnitude (Fig. 4c) and the measurements limited to the observational period (Fig. 3), their magnitude nevertheless suggests an important, yet overlooked, $\mathrm{O}_{2}$ pathway.

We performed a simple 1-D BBL mass balance to investigate the relevance to the local $\mathrm{O}_{2}$ balance during our observational period. Here, we defined the apparent (measured) $\mathrm{O}_{2}$ loss rate in the BBL $\partial\left[\mathrm{O}_{2}\right] / \partial t$ as the consequence of $\mathrm{O}_{2}$ replenishment from $F_{\theta}$ and the $\mathrm{O}_{2}$ utilization via sediment $\mathrm{O}_{2}$ uptake rate (SUR) and water column organic matter respiration $(R)$ expressed as

$$
\frac{\partial\left[\mathrm{O}_{2}\right]}{\partial t} \frac{V}{A}=\left|F_{\theta}\right|-|\mathrm{SUR}|-|R|\left\{\mathrm{mmol} \mathrm{m}^{-2} \mathrm{~d}^{-1}\right\} .
$$


The mass balance was constrained to the (assumed) wellmixed $35 \mathrm{~m}$ deep BBL section of area, $A=1 \mathrm{~m}^{2}$ with a volume $V=35 \mathrm{~m}^{3}$. We further assumed negligible horizontal $\mathrm{O}_{2}$ gradients (as observed from the CTD casts), and thus a net zero horizontal $\mathrm{O}_{2}$ advective transport.

The average SUR for the same time period and location, obtained from parallel eddy correlation measurements, was $\sim-10 \mathrm{mmol} \mathrm{m}^{-2} \mathrm{~d}^{-1}$ (McGinnis et al., 2014). The SUR was consistent with the average SUR at Oyster Grounds reported by Neubacher et al. (2011), $-9.8 \mathrm{mmol} \mathrm{m}^{-2} \mathrm{~d}^{-1}$, and with modeled SURs at the same site (average $-8.6 \mathrm{mmol} \mathrm{m}^{-2} \mathrm{~d}^{-1}$; Meire et al., 2013). The apparent BBL $\mathrm{O}_{2}$ loss of $-0.42 \mu \mathrm{mol} \mathrm{kg}{ }^{-1} \mathrm{~d}^{-1}$ was determined from the POZ lander $\mathrm{O}_{2}$ optode time series (Fig. $5 \mathrm{a}$ ) over $52 \mathrm{~h}$, $\left(R^{2}=0.60\right)$. Though limited to our short observational period, the vertically integrated apparent $\mathrm{BBL} \mathrm{O}_{2}$ loss was about $-15 \mathrm{mmol} \mathrm{m}^{-2} \mathrm{~d}^{-1}$ and thus within $2 \%$ of the nearby North Dogger average presented by Greenwood et al. (2010). Based on Eq. (6) and using the observed BBL $\mathrm{O}_{2}$ loss rate, $F_{\theta}$ and SUR, the water column respiration, $R$ was calculated to be $\sim-60 \mathrm{mmol} \mathrm{m}^{-2} \mathrm{~d}^{-1}$. This implies that without the $\mathrm{O}_{2}$ replenishment, the apparent $\mathrm{BBL} \mathrm{O}_{2}$ loss would be $\sim-2 \mu \mathrm{mol} \mathrm{kg} \mathrm{kg}^{-1} \mathrm{~d}^{-1}$ and thus 4 times higher than observed. Our results indicated that the total respiration in the bottom water was therefore $\sim-70 \mathrm{mmol} \mathrm{m}^{-2} \mathrm{~d}^{-1}$ (SUR $+R$ ), with about $14 \%$ of the organic carbon mineralization occurring in the sediment and $86 \%$ in the BBL.

\section{Discussion}

During our 3-day observational period, we found that the baroclinic near-inertial wave in the interior layer was the main contributor to the detected enhanced shear (Fig. 3d) and the observed elevated vertical $\mathrm{O}_{2}$ flux to the BBL (Fig. 6). As near-inertial waves decay after a few weeks, it should be noted that we observed a rather special situation, and that vertical $\mathrm{O}_{2}$ fluxes will not likely be as highly elevated during periods when near-inertial waves are not present.

Within this context, we (1) discuss the turbulent mechanisms leading to these thermocline $\mathrm{O}_{2}$ fluxes and mechanisms promoting the formation of the $\mathrm{O}_{2}$ maximum zone in terms of primary productivity, (2) discuss the implication for the local $\mathrm{O}_{2} \mathrm{BBL}$ dynamics and carbon budget, (3) elaborate on factors that can ultimately influence $\mathrm{O}_{2}$ depletion in the North Sea and other seasonally stratified shelf seas.

\subsection{Thermocline mixing}

The expansive North Sea thermocline $\left(1-5 \times 10^{5} \mathrm{~km}^{2}\right.$; Meyer et al., 2011) has been regarded as being in a state of marginal stability, where additional sources of shear could lead to increased thermocline mixing (e.g., van Haren et al., 1999). Itsweire et al. (1989) showed that layers of strong shear are likely to be found where strong stratification occurs.
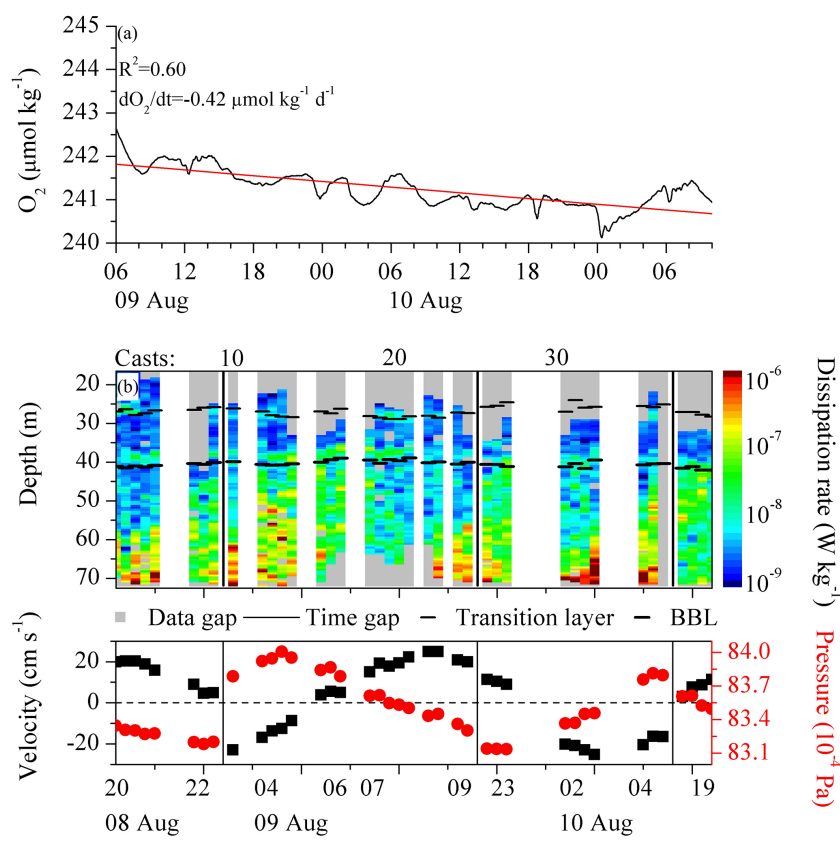

Figure 5. BBL dissolved oxygen time series and turbulence contour. (a) Near-seafloor BBL $\mathrm{O}_{2}$ concentration changes over the observational period from the POZ lander. Red line indicates the estimated apparent linear $\mathrm{O}_{2}$ loss. (b, top) Turbulence contour plot of all MSS90 casts together with the temperature layers. Thin and thick dashed lines represent the transition layer to the interior layer interface and the interior layer to the BBL interface, respectively. Grey spots indicate data missing due to uncompleted profiles (casts 16-23), unsuccessful profiles (cast 36), or flagged as bad based on spikes, collisions and suspected contamination due to ship activity. The vertical black lines indicate the transition (time gaps) between consecutive profile ensembles. (b, bottom) Background information on bottom current and hydrostatic pressure during the casts. Both velocity and pressure data were collected by the deployed POZ lander. Note that as a result of the time gaps between the consecutive MSS90 casts (see Fig. 3a) the timescale is not linear.

Generally, in the absence of varying topography and sloping boundaries, the major sources of shear in the thermocline are considered to be internal tides and near-inertial oscillations (see Rippeth, 2005). Sharples et al. (2007) demonstrated that internal tidally driven thermocline mixing enhanced diapycnal nutrient fluxes, the overall productivity in the thermocline and the associated carbon export to the BBL.

The occurrence of near-inertial oscillations in shelf seas during the stratified season has been reported in several studies from the North Sea (van Haren et al., 1999; Knight et al., 2002) and in other shelf seas (e.g., Rippeth et al., 2002; MacKinnon and Gregg, 2005). During the presence of baroclinic inertial waves in the water column, periods of enhanced shear have been observed in the western Irish Sea (Rippeth et al., 2009), the Celtic Sea (Palmer et al., 2008) and the northern North Sea (Burchard and Rippeth, 2009). These 
take the form of shear spikes, which occur approximately every inertial period and in bursts lasting several days.

While we mainly attributed the observed enhanced turbulent mixing to the occurrence of a near-inertial wave, the site's physical setting has further implications for mixing processes in the thermocline. In the Northern Hemisphere, sites with anti-cyclonic tides, such as Tommeliten, are often characterized by an increased vertical extension of the $\mathrm{BBL}$ and higher BBL dissipation rates than comparable cyclonic sites (see Simpson and Tinker, 2009). As a result of this enhanced BBL thickness, we observed sporadically elevated thermocline turbulence resulting from tidal-driven bottom turbulence propagating vertically towards the thermocline (Fig. 5b). A study by Burchard and Rippeth (2009) also reported that short-lived thermocline shear spikes can arise due to the alignment of the surface wind stress, bulk shear and bed stress vectors in the presence of baroclinic nearinertial motions and barotropic tidal currents. These mechanisms are stronger with anti-cyclonic tides. Although all the features required for shear spike generation were present during the observational period, the two-layer mechanism described by these authors would require a more complex water column structure to be applicable to the Tommeliten site.

The site's water column structure clearly showed the occurrence of a $10 \mathrm{~m}$ thick transition layer (Fig. 2a). This layer represents the region of the water column where mixing turns from elevated in the SBL to strongly reduced in the interior layer (Ferrari and Boccaletti, 2004). The transition layer is therefore an obligate pathway for solute and heat exchange between the SBL and the interior layer (Ferrari and Boccaletti, 2004; Rhein et al., 2010) and has been reported to be a region of enhanced shear and near-inertial wave activity (Dohan and Davis, 2011). Although the presented data did not allow quantification of the $\mathrm{O}_{2}$ exchange across the transition layer, such contribution might be considerable and thus highly relevant for the cycling of $\mathrm{O}_{2}$ and $\mathrm{CO}_{2}$ in the upper water column, which in turn could have direct biological implications.

\section{2 $\mathrm{BBL} \mathrm{O}_{2}$ dynamics}

Ultimately, observed $\mathrm{O}_{2}$ depletion in the BBL of the central North Sea depends on the supply of organic matter, the rate of carbon mineralization and the flux of $\mathrm{O}_{2}$ to the bottom water either from horizontal advection or turbulent vertical transport. Our study investigated the significance of turbulent vertical $\mathrm{O}_{2}$ fluxes to the BBL, which has been previously overlooked in shelf sea carbon balances. Studies focusing on $\mathrm{O}_{2}$ replenishment in the BBL through the thermocline are limited to freshwater systems (e.g., Bouffard et al., 2013; Kreling et al., 2014). In a large, stratified water body such as Lake Erie, $\mathrm{O}_{2}$ transport from the thermocline to the hypolimnion was found to be substantial, with a magnitude comparable to $\sim 18 \%$ of the hypolimnetic $\mathrm{O}_{2}$ utilization rate over the whole stratification period (Bouffard et al., 2013).

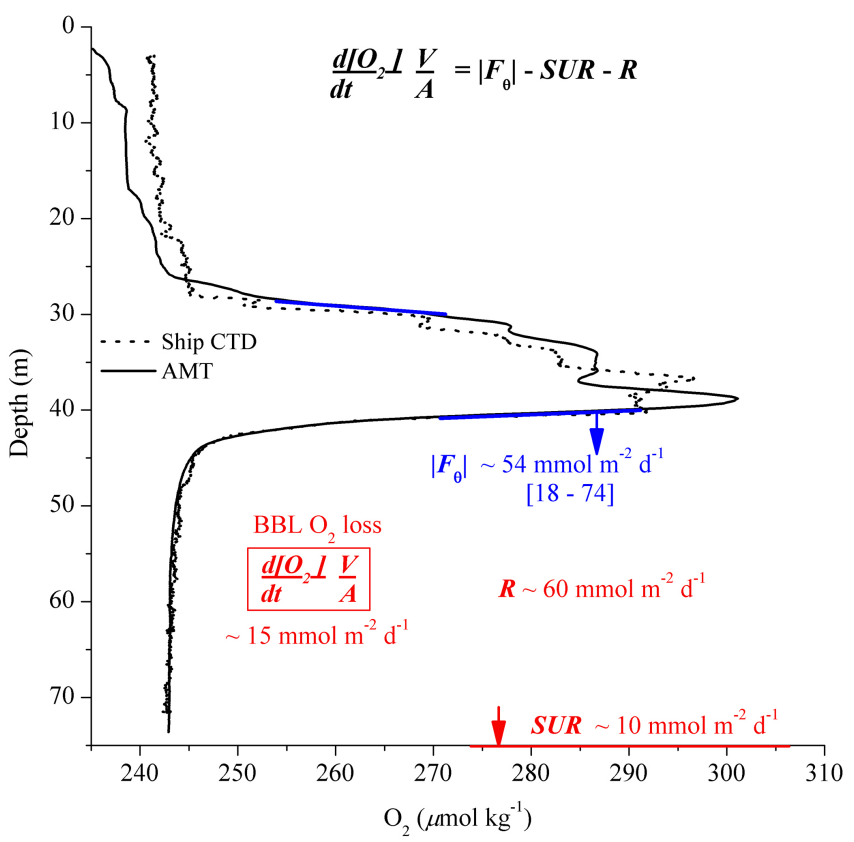

Figure 6. Main $\mathrm{O}_{2}$ fluxes in this study. The ranges shown for the interior layer $\mathrm{O}_{2}$ fluxes refer to the associated uncertainty and intermittency levels. The sediment $\mathrm{O}_{2}$ uptake rates (SUR) are based on eddy correlation (EC) measurements (McGinnis et al., 2014), while central North Sea apparent $\mathrm{BBL} \mathrm{O}_{2}$ loss is based on Greenwood et al. (2010) and this study. Representative $\mathrm{O}_{2}$ profiles are based on the AMT sensor on the MSS profiler (solid line) and ship CTD (dotted line). Note that while the $\mathrm{O}_{2}$ profiles showed differences in absolute concentration within the thermocline, the actual $\mathrm{O}_{2}$ gradients within the thermocline-BBL oxycline are comparable.

Horizontal $\mathrm{O}_{2}$ gradients and associated horizontal advective $\mathrm{O}_{2}$ fluxes were not quantified in this study. Our data suggest, however, that such fluxes would not significantly contribute to the $\mathrm{O}_{2}$ balance at the Tommeliten site. $\mathrm{BBL} \mathrm{O}_{2}$ concentration time series (Fig. 5a) did not show any variability at the tidal and/or inertial frequencies, implying that horizontal $\mathrm{O}_{2}$ gradients were small. Additionally, mean currents in the BBL were small $\left(\sim 2 \mathrm{~cm} \mathrm{~s}^{-1}\right)$ compared to the tidal amplitudes. This, in conjunction with weak horizontal $\mathrm{O}_{2}$ gradients, suggests that horizontal advective $\mathrm{O}_{2}$ fluxes during our observational period are negligible compared to the turbulent $\mathrm{O}_{2}$ flux from the thermocline.

Based on the above, we can argue that the $\mathrm{O}_{2}$ dynamics during the stratified period are more complicated than previously regarded. To maintain an excess of $\mathrm{O}_{2}$ in the thermocline, primary producers require adequate nutrient entrainment from the bottom water to fuel potential new production. The resulting increase in (new) productivity and subsequent export to the bottom water could boost the carbon turnover estimates substantially. Using a $1: 1 \mathrm{O}_{2}$ utilization to carbon remineralization (see Canfield, 1993), Greenwood et al. (2010) inferred the average BBL carbon remineralization rate at the nearby North Dogger to be $15 \mathrm{mmol} \mathrm{m}^{-2} \mathrm{~d}^{-1}$, 
or $180 \mathrm{mg} \mathrm{Cm}^{-2} \mathrm{~d}^{-1}$. Similar results for a typical northwest European shelf sea were obtained via modeling by Sharples (2008), who reported rates ranging from $\sim 35$ to $\sim 200 \mathrm{mg} \mathrm{m}^{-2} \mathrm{~d}^{-1}$ for neap and spring tide, respectively. Their study, however, did not include the daily tidal variation, and thus rates could be much higher on shorter timescales.

With the absence of targeted long-term studies focusing on $\mathrm{O}_{2}$ and carbon dynamics in the thermocline and $\mathrm{BBL}$, we can only speculate on the long-term fate of the $\mathrm{BBL}_{2}$ and its replenishment from the thermocline by vertical $\mathrm{O}_{2}$ fluxes $\left(F_{\theta}\right)$. It seems possible that the overall net BBL water column $\mathrm{O}_{2}$ respiration, $R$, is higher than previously thought, suggesting a much higher carbon turnover than inferred from the apparent $\mathrm{O}_{2}$ loss rate. Based on Eq. (6), the BBL carbon remineralization (and export to the BBL) would be on the order of nearly $850 \mathrm{mg} \mathrm{C} \mathrm{m}^{-2} \mathrm{~d}^{-1}$, a factor of nearly 5 higher than reported by Greenwood et al. (2010). However, the same turbulent transport that supports the $\mathrm{O}_{2}$ export from the DCM to the BBL also supports BBL nutrient import to the DCM (Fig. 6). The higher import of nutrients to the DCM likely promotes additional primary production and a subsequent increase in organic matter (OM) export to the BBL. In such a scenario, the $\mathrm{O}_{2}$ flux to the BBL presented in this "snapshot" study will be associated with additional OM to the BBL, and therefore lead to a temporary increased remineralization that offsets the increased $F_{\theta}$. While the overall effect is an increase in carbon turnover, this process would not result in any observable change in the decreasing $\mathrm{O}_{2}$ trend (apparent $\mathrm{O}_{2}$ loss rate).

\subsection{Causes and controls on BBL $\mathrm{O}_{2}$ depletion}

According to Boers (2005), for $\mathrm{BBL}_{2}$ to decrease throughout the stratified season, there must be suitable physical conditions, biomass production, nutrient input and continued benthic $\mathrm{O}_{2}$ uptake. SUR, and thus the sediment nutrient release and organic carbon mineralization have been shown to be strongly tidally driven (McGinnis et al., 2014). Therefore, we briefly discuss the potential tidal impact driving the overall carbon cycling and suggest factors that may promote the development of lower $\mathrm{BBL} \mathrm{O}_{2}$ concentrations during the stratification period.

Tidal forcing on diapycnal constituent fluxes and primary production have been explored by e.g., Sharples et al. (2007, 2008). The authors showed that spring-neap tide drives nutrient fluxes between the BBL and the DCM at the thermocline and the carbon export. Based on our velocity measurements and estimated $\mathrm{O}_{2}$ fluxes, we can expect similar patterns corresponding to semidiurnal tidal fluctuations. Blauw et al. (2012) investigated fluctuating phytoplankton concentrations in relation to tidal drivers and found that, in the southern North Sea, chlorophyll fluctuations correlated with the typical tidal current speed periods, the semidiurnal tidal cycle, in addition to the day-night and spring-neap periods. During most of the year, chlorophyll and suspended partic- ulate matter fluctuated in phase with tidal current speed and indicated alternating periods of sinking and vertical mixing of algae and suspended matter with tidal cycles. Thus, these results suggest that in addition to the spring-neap tidal cycles, we can expect a semidiurnal tidal-driven export of carbon and $\mathrm{O}_{2}$ from the DCM to the BBL, and entrainment of nutrients that strongly vary based on a timescale related to the semi-diurnal tidal cycle.

The flux of $\mathrm{O}_{2}$ from the DCM production zone downward to the BBL could set the lower limit of the $\mathrm{BBL} \mathrm{O}_{2}$ concentration, and thus the $\mathrm{O}_{2}$ depletion level, during the stratification period. If there is little isolation between the zone of production and the zone of mineralization, then the net $\mathrm{O}_{2}$ production and $\mathrm{O}_{2}$ utilization would nearly balance. In such case, the apparent $\mathrm{O}_{2}$ loss in the BBL would either be negligible or very small, depending whether the SUR, which is largely particulate organic matter driven, will be balanced by the ventilation from the thermocline. However, historically decreasing BBL $\mathrm{O}_{2}$ concentrations within the North Sea (Queste et al., 2013) point to an increasing disconnect between the primary $\mathrm{O}_{2}$ production zone and the mineralization zone. Greenwood et al. (2010) state that stratification is an important factor which determines susceptibility to $\mathrm{O}_{2}$ depletion, especially in their nearby study site Oyster Grounds.

Surveys on the North Sea have shown that the regions with the lowest $\mathrm{BBL} \mathrm{O}_{2}$ concentrations are generally characterized by the strongest stratification (see Queste et al., 2013), with the lowest values $\left(\sim 100 \mu \mathrm{mol} \mathrm{kg}{ }^{-1}\right)$ reported to occur during particularly calm and warm weather (see Boers, 2005; Weston et al., 2008). Strong gradients in the thermocline associated with warmer temperature are suggested to limit the $\mathrm{O}_{2}$ flux to the BBL (Weston et al., 2008). This points to potential future $\mathrm{O}_{2}$ depletion resulting from increasing temperatures leading to both stronger stratification and a longer stratification season (Lowe et al., 2009). However, it could be argued that if $\mathrm{O}_{2}$ fluxes between the DCM and BBL were suppressed, then the upward nutrient fluxes would be similarly suppressed, thus inhibiting primary production and reducing the potential for $\mathrm{O}_{2}$ deficits.

\subsection{Biological perspective}

The occurrence of stronger stratification and subsequently reduced turbulent mixing could alter algal populations (Hickman et al., 2009), potentially favoring migrating/swimming phytoplankton. Examples of these migrating phytoplankton species, armored dinoflagellates, are extensively found in the DCM of the central and northern North Sea during the summer months; their abundance was found to be largely determined by the local hydrodynamic conditions (Reid et al., 1990). In calm conditions, which are typically associated with stronger stratification, there are often blooms of migrating dinoflagellates which have access to the large nutrient pool in the deeper water and can out-compete non-migrating species for both light and nutrients. Stronger turbulent mix- 
ing, in contrast, has been suggested to interfere with their swimming abilities (see Jephson et al., 2012, and references therein).

Due to the limited observational period of this study and our measurement approach, we were not able to observe algal migration. However, based on the above literature observations of algae in the central North Sea, we propose that algal migration could be an overlooked mechanism that contributes to diminishing bottom water $\mathrm{O}_{2}$ levels. By promoting an upward shift of the DCM and moving the associated $\mathrm{O}_{2}$ production higher in the thermocline where turbulence levels are reduced, while still maintaining comparable production rates, even a few meters' upward shift would substantially reduce turbulent $\mathrm{O}_{2}$ fluxes to the BBL, while maintaining similar rates of carbon export (settling armored dinoflagellates). Studies on climate change impacts on the North Sea have suggested that $\mathrm{O}_{2}$ loss in the bottom waters would mainly result from a strengthening of the stratification and $\mathrm{O}_{2}$ solubility reduction with increasingly warmer waters (e.g., Meire et al., 2013). In those scenarios, the intricate interplay between local tidally driven processes, water column structure, biogeochemical cycling and active phytoplankton migration have not been considered nor quantified. The proposed mechanism could contribute to the observed decreasing $\mathrm{O}_{2}$ levels in the North Sea water column; however, further detailed studies are obviously necessary to test and quantify this effect, and the results described in this study, at the seasonal level.

\section{The Supplement related to this article is available online at doi:10.5194/bg-13-1609-2016-supplement.}

\begin{abstract}
Acknowledgements. We are thankful to the captain and crew members of the R/V Celtic Explorer for their outstanding collaboration and support during the survey, Uwe Koy and Rudolf Link for their logistic support, and Jens Schafstall, Tim Fischer and Markus Faulhaber for their help in data collection and processing. We are grateful for the technical development and support in deployment of the benthic chamber by Ralf Schwarz, Sergiy Cherednichenko and the ROV Kiel 6000 team. Financial support was provided by the Sonderforschungsbereich (SFB) 754 "Climate-Biogeochemisty in the tropical Ocean", SFB 574 "Volatiles and Fluids in Subduction Zones" and by the Excellence Cluster "Future Ocean" (project 2009/1 CP 0915, LR), supported by the Deutsche Forschungsgemeinschaft (DFG). Additional founding was provided by the National Environmental Research Council (NERC, project NE/J011681/1). The cruise was financed by Wintershall within the Fluid and Gas Seepage in the Southern German North Sea (SDNS) project.
\end{abstract}

The article processing charges for this open-access publication were covered by a Research

Centre of the Helmholtz Association.
Edited by: B. Currie

\section{References}

Batchelor, G. K.: The theory of homogeneous turbulence, Cambridge University Press, Cambridge, 1953.

Best, M. A., Wither, A. W., and Coates, S.: Dissolved oxygen as a physico-chemical supporting element in the Water Framework Directive, Mar. Pollut. Bull., 55, 53-64, doi:10.1016/j.marpolbul.2006.08.037, 2007.

Blauw, A. N., Beninca, E., Laane, R. W. P. M., Greenwood, N., and Huisman, J.: Dancing with the tides: fluctuations of coastal phytoplankton orchestrated by different oscillatory modes of the tidal cycle, Plos One, 7, e49319, doi:10.1371/journal.pone.0049319, 2012.

Boers, M.: Effects of a deep sand extraction pit, Final report of the PUTMOR measurements at the Lowered Dump Site, Rijkswaterstaat, the Netherlands, RIKZ/2005.001, 87, 2005.

Bouffard, D., Ackerman, J. D., and Boegman, L.: Factors affecting the development and dynamics of hypoxia in a large shallow stratified lake: hourly to seasonal patterns, Water Resour. Res., 49, 2380-2394, doi:10.1002/wrcr.20241, 2013.

Brandt, P., Bange, H. W., Banyte, D., Dengler, M., Didwischus, S.-H., Fischer, T., Greatbatch, R. J., Hahn, J., Kanzow, T., Karstensen, J., Körtzinger, A., Krahmann, G., Schmidtko, S., Stramma, L., Tanhua, T., and Visbeck, M.: On the role of circulation and mixing in the ventilation of oxygen minimum zones with a focus on the eastern tropical North Atlantic, Biogeosciences, 12, 489-512, doi:10.5194/bg-12-489-2015, 2015.

Burchard, H. and Rippeth, T. P.: Generation of bulk shear spikes in shallow stratified tidal seas, J. Phys. Oceanogr., 39, 969-985, doi:10.1175/2008JPO4074.1, 2009.

Canfield, D. E.: Organic matter oxidation in marine sediments, in: Interactions of $\mathrm{C}, \mathrm{N}, \mathrm{P}$ and $\mathrm{S}$ biogeochemical cycles and global change, edited by: Wollast, R., Mackenzie, F. T., and Chou, L., Springer, Berlin, 333-363, 1993.

Chan, F., Barth, J. A., Lubchenco, J., Kirincich, A., Weeks, H., Peterson, W. T., and Menge, B. A.: Emergence of anoxia in the California current large marine ecosystem, Science, 319, 920-920, doi:10.1126/Science.1149016, 2008.

Crawford, W. R. and Pena, M. A.: Declining oxygen on the British Columbia continental shelf, Atmos. Ocean., 51, 88-103, doi:10.1080/07055900.2012.753028, 2013.

Diaz, R. J.: Overview of hypoxia around the world, J. Environ. Qual., 30, 275-281, doi:10.2134/jeq2001.302275x, 2001.

Diaz, R. J. and Rosenberg, R. : Spreading dead zones and consequences for marine ecosystems, Science, 321, 926-929, doi:10.1126/Science.1156401, 2008.

Dohan, K. and Davis, R. E.: Mixing in the transition layer during two storm events, J. Phys. Oceanogr., 41, 42-66, doi:10.1175/2010jpo4253.1, 2011.

Efron, B.: 1977 Rietz lecture - bootstrap methods - another look at the jackknife, Ann. Stat., 7, 1-26, 1979.

Ferrari, R. and Boccaletti, G.: Eddy-mixed layer interactions in the ocean, Oceanography, 17, 12-21, doi:10.5670/oceanog.2004.26, 2004. 
Ferrari, R. and Polzin, K. L.: Finescale structure of the T-S relation in the eastern North Atlantic, J. Phys. Oceanogr., 35, 1437-1454, doi:10.1175/JPO2763.1, 2005.

Fischer, T., Banyte, D., Brandt, P., Dengler, M., Krahmann, G., Tanhua, T., and Visbeck, M.: Diapycnal oxygen supply to the tropical North Atlantic oxygen minimum zone, Biogeosciences, 10, 5079-5093, doi:10.5194/bg-10-5079-2013, 2013.

Fofonoff, N. P.: Physical properties of seawater: A new salinity scale and equation of state for seawater, J. Geophys. Res., 90, 3332-3342, doi:10.1029/Jc090ic02p03332, 1985.

Glud, R. N.: Oxygen dynamics of marine sediments, Mar. Biol. Res., 4, 243-289, doi:10.1080/17451000801888726, 2008.

Grantham, B. A., Chan, F., Nielsen, K. J., Fox, D. S., Barth, J. A., Huyer, A., Lubchenco, J., and Menge, B. A.: Upwellingdriven nearshore hypoxia signals ecosystem and oceanographic changes in the northeast Pacific, Nature, 429, 749-754, doi:10.1038/Nature02605, 2004.

Greenwood, N., Parker, E. R., Fernand, L., Sivyer, D. B., Weston, K., Painting, S. J., Kröger, S., Forster, R. M., Lees, H. E., Mills, D. K., and Laane, R. W. P. M.: Detection of low bottom water oxygen concentrations in the North Sea; implications for monitoring and assessment of ecosystem health, Biogeosciences, 7, 1357-1373, doi:10.5194/bg-7-1357-2010, 2010.

Hickman, A. E., Holligan, P. M., Moore, C. M., Sharples, J., Krivtsov, V., and Palmer, M. R.: Distribution and chromatic adaptation of phytoplankton within a shelf sea thermocline, Limnol. Oceanogr., 54, 525-536, doi:10.4319/lo.2009.54.2.0525, 2009.

Hovland, M. and Judd, A.: Seabed pockmarks and seepage: Impact on geology, biology and the marine environment, Graham and Trotman, London, 1988.

Itsweire, E. C., Osborn, T. R., and Stanton, T. P.: Horizontal distribution and characteristics of shear layers in the seasonal thermocline, J. Phys. Oceanogr., 19, 302-320, doi:10.1175/15200485(1989)019<0301:HDACOS>2.0.CO;2, 1989.

Ivey, G. N. and Imberger, J.: On the nature of turbulence in a stratified fluid, Part I: The energetics of mixing, J. Phys. Oceanogr., 21, 650-658, doi:10.1175/15200485(1991)021<0650:OTNOTI>2.0.CO;2, 1991.

Jephson, T., Carlsson, P., and Fagerberg, T.: Dominant impact of water exchange and disruption of stratification on dinoflagellate vertical distribution, Estuar. Coast. Shelf S., 112, 198-206, doi:10.1016/j.ecss.2012.07.020, 2012.

Jørgensen, B. B. and Revsbech, N. P.: Diffusive boundary layers and the oxygen uptake of sediments and detritus, Limnol. Oceanogr., 30, 111-122, doi:10.4319/lo.1985.30.1.0111, 1985.

Kemp, W. M., Testa, J. M., Conley, D. J., Gilbert, D., and Hagy, J. D.: Temporal responses of coastal hypoxia to nutrient loading and physical controls, Biogeosciences, 6, 2985-3008, doi:10.5194/bg-6-2985-2009, 2009.

Knight, P. J., Howarth, M. J., and Rippeth, T. P.: Inertial currents in the northern North Sea, J. Sea Res., 47, 269-284, doi:10.1016/S1385-1101(02)00122-3, 2002.

Kreling, J., Bravidor, J., McGinnis, D. F., Koschorreck, M., and Lorke, A.: Physical controls of oxygen fluxes at pelagic and benthic oxyclines in a lake, Limnol. Oceanogr., 59, 1637-1650, doi:10.4319/lo.2014.59.5.1637, 2014.

Lorke, A., Umlauf, L., and Mohrholz, V.: Stratification and mixing on sloping boundaries, Geophys. Res. Lett., 35, L14610, doi:10.1029/2008GL034607, 2008.
Lowe, J. A., Howard, T. P., Pardaens, A., Tinker, J., Holt, J., Wakelin, S., Milne, G., Leake, J., Wolf, J., Horsburgh, K., Reeder, T., Jenkins, G., Ridley, J., Dye, S., and Bradley, S.: UK Climate Projections science report: Marine and coastal projections, Met Office Hadley Centre, available at: http://ukclimateprojections. metoffice.gov.uk/22530 (last access: 11 March 2016), 2009.

MacKinnon, J. A. and Gregg, M. C.: Near-inertial waves on the New England shelf: The role of evolving stratification, turbulent dissipation, and bottom drag, J. Phys. Oceanogr., 35, 2408-2424, doi:10.1175/JPO2822.1, 2005.

McGinnis, D. F., Sommer, S., Lorke, A., Glud, R. N., and Linke, P.: Quantifying tidally driven benthic oxygen exchange across permeable sediments: An aquatic eddy correlation study, J. Geophys. Res.-Oceans, 119, 6918-6932, doi:10.1002/2014JC010303, 2014.

Meire, L., Soetaert, K. E. R., and Meysman, F. J. R.: Impact of global change on coastal oxygen dynamics and risk of hypoxia, Biogeosciences, 10, 2633-2653, doi:10.5194/bg-10-2633-2013, 2013.

Meyer, E. M. I., Pohlmann, T., and Wiesse, R.: Thermodynamic variability and change in the North Sea (1948-2007) derived from a multidecadal hindcast, J. Marine Syst., 86, 35-44, doi:10.1016/j.jmarsys.2011.02.001, 2011.

Neubacher, E. C., Parker, R. E., and Trimmer, M.: Shortterm hypoxia alters the balance of the nitrogen cycle in coastal sediments, Limnol. Oceanogr., 56, 651-665, doi:10.4319/lo.2011.56.2.0651, 2011.

North Sea Task Force: North Sea Quality Status Report, Report No.: 187234905 6, London: Oslo and Paris Commissions, 1993.

Osborn, T. R.: Estimates of the local rate of vertical diffusion from dissipation measurements, J. Phys. Oceanogr., 10, 83-89, doi:10.1175/1520-0485(1980)010<0083:EOTLRO>2.0.CO;2, 1980.

OSPAR (Oslo-Paris convention for the protection of the marine environment of the North-East Atlantic): EcoQO Handbook - Handbook for the application of ecological quality objectives in the North Sea, Report No.: 978-1-905859-46-7, 2nd Edn., OSPAR Biodiversity Series 2009/307, available at: http://www.ospar.org/v_publications/browse.asp (last access: 11 March 2016), 2009.

OSPAR (Oslo-Paris convention for the protection of the marine environment of the North-East Atlantic): Quality Status Report 2010, Report No: 978-1-906840-44-0, OSPAR Commission, London, available at: http://qsr2010.ospar.org/en/index.html (last access: 11 March 2016), 2010.

Otto, L., Zimmerman, J. T. F., Furnes, G. K., Mork, M., Saetre, R., and Becker, G.: Review of the physical oceanography of the North Sea, Neth. J. Sea Res., 26, 161-238, doi:10.1016/00777579(90)90090-4, 1990.

Palmer, M. R., Rippeth, T. P., and Simpson, J. H.: An investigation of internal mixing in a seasonally stratified shelf sea, J. Geophys. Res., 113, C12005, doi:10.1029/2007JC004531, 2008.

Pfannkuche, O. and Linke, P.: GEOMAR landers as long-term deepsea observatories, Sea Technol., 44, 50-55, 2003.

Pingree, R. D., Holligan, P. M., and Mardell, G. T.: The effect of vertical stability on phytoplankton distributions in the summer on the Northwest European Shelf, Deep-Sea Res., 25, 1011-1028, doi:10.1016/0146-6291(78)90584-2, 1978. 
Prandke, H. and Stips, A.: Test measurements with an operational microstructure-turbulence profiler: Detection limit of dissipation rates, Aquat. Sci., 60, 191-209, doi:10.1007/s000270050036, 1998.

Queste, B. Y., Fernand, L., Jickells, T. D., and Heywood, K. J.: Spatial extent and historical context of North Sea oxygen depletion in August 2010, Biogeochemistry, 113, 53-68, doi:10.1007/s10533-012-9729-9, 2013.

Radach, G. and Lenhart, H. J.: Nutrient dynamics in the North Sea: Fluxes and budgets in the water column derived from ERSEM, Neth. J. Sea Res., 33, 301-335, doi:10.1016/00777579(95)90051-9, 1995

Reid, P. C., Lancelot, C., Gieskes, W. W. C., Hagmeier, E., and Weichart, G.: Phytoplankton of the North Sea and its dynamics - a review, Neth. J. Sea Res., 26, 295-331, doi:10.1016/00777579(90)90094-W, 1990.

Rhein, M., Dengler, M., Sültenfuß, J., Hummels, R., Hüttl-Kabus, S., and Bourles, B.: Upwelling and associated heat flux in the equatorial Atlantic inferred from helium isotope disequilibrium, J. Geophys. Res., 115, C08021, doi:10.1029/2009JC005772, 2010.

Rippeth, T. P., Simpson, J. H., Player, R., and Garcia, M. C.: Current oscillations in the diurnal-inertial band on the Catalonian Shelf in spring, Cont. Shelf Res., 22, 247-265, doi:10.1016/S02784343(01)00056-5, 2002.

Rippeth, T. P.: Mixing in seasonally stratified shelf seas: A shifting paradigm, Philos. T. R. Soc. A, 363, 2837-2854, doi:10.1098/rsta.2005.1662, 2005.

Rippeth, T. P., Wiles, P., Palmer, M. R., Sharples, J., and Tweddle, J.: The diapcynal nutrient flux and shear-induced diapcynal mixing in the seasonally stratified western Irish Sea, Cont. Shelf Res., 29, 1580-1587, doi:10.1016/j.csr.2009.04.009, 2009.

Schafstall, J., Dengler, M., Brandt, P., and Bange, H.: Tidalinduced mixing and diapycnal nutrient fluxes in the Mauritanian upwelling region, J. Geophys. Res.-Oceans, 115, C10014, doi:10.1029/2009jc005940, 2010.

Schneider von Deimling, J., Greinert, J., Chapman, N. R., Rabbel, W., and Linke, P.: Acoustic imaging of natural gas bubble ebullition in the North Sea: Sensing the temporal, spatial and activity variability, Limnol. Oceanogr.-Meth., 8, 155-171, doi:10.4319/lom.2010.8.155, 2010.

Sharples, J., Moore, C. M., Rippeth, T. P., Holligan, P. M., Hydes, D. J., Fisher, N. R., and Simpson, J. H.: Phytoplankton distribution and survival in the thermocline, Limnol. Oceanogr., 46, 486-496, doi:10.4319/lo.2001.46.3.0486, 2001.

Sharples, J., Tweddle, J. F., Green, J. A. M., Palmer, M. R., Kim, Y. N., Hickman, A. E. Holligan, P. M., Moore, C. M., Rippeth, T. P., Simpson, J. H., and Krivtsov, V.: Spring-neap modulation of internal tide mixing and vertical nitrate fluxes at a shelf edge in summer, Limnol. Oceanogr., 52, 1735-1747, doi:10.4319/lo.2007.52.5.1735, 2007.
Sharples, J.: Potential impacts of the spring-neap tidal cycle on shelf sea primary production, J. Plankton Res., 30, 183-197, doi:10.1093/plankt/fbm088, 2008.

Shih, L. H., Koseff, J. R., Ivey, G. N., and Ferziger, J. H.: Parameterization of turbulent fluxes and scales using homogeneous sheared stably stratified turbulence simulations, J. Fluid Mech., 525, 193214, doi:10.1017/S0022112004002587, 2005.

Simpson, J. H. and Tinker, J. P.: A test of the influence of tidal stream polarity on the structure of turbulent dissipation, Cont. Shelf Res., 29, 320-332, doi:10.1016/j.csr.2007.05.013, 2009.

Smyth, W. D., Moum, J. N., and Caldwell, D. R.: The efficiency of mixing in turbulent patches: inferences from direct simulations and microstructure observations, J. Phys. Oceanogr., 31, 1969-1992, doi:10.1175/15200485(2001)031<1969:TEOMIT>2.0.CO;2, 2001.

St. Laurent, L. and Schmitt, R. W.: The contribution of salt fingers to vertical mixing in the North Atlantic Tracer Release Experiment, J. Phys. Oceanogr., 29, 1404-1424, doi:10.1175/15200485(1999)029<1404:TCOSFT>2.0.CO;2, 1999.

Thomas, H., Bozec, Y., de Baar, H. J. W., Elkalay, K., Frankignoulle, M., Schiettecatte, L.-S., Kattner, G., and Borges, A. V.: The carbon budget of the North Sea, Biogeosciences, 2, 87-96, doi:10.5194/bg-2-87-2005, 2005.

van Haren, H., Mass, L., Zimmerman, J. T. R., Ridderinkhof, H., and Malschaert, H.: Strong inertial currents and marginal internal wave stability in the central North Sea, Geophys. Res. Lett., 26, 2993-2996, doi:10.1029/1999GL002352, 1999.

Vaquer-Sunyer, R. and Duarte, C. M.: Thresholds of hypoxia for marine biodiversity, P. Natl. Acad. Sci. USA., 105, 1545215457, doi:10.1073/pnas.0803833105, 2008.

Wanninkhof, R.: Relationship between wind speed and gas exchange over the ocean, J. Geophys. Res.-Oceans, 97, 7373-7382, doi:10.1029/92jc00188, 1992.

Weston, K., Fernand, L., Mills, D. K., Delahunty, R., and Brown, J.: Primary production in the deep chlorophyll maximum of the central North Sea, J. Plankton Res., 27, 909-922, doi:10.1093/plankt/fbi064, 2005.

Weston, K., Greenwood, N., Fernand, L., Pearce, D. J., and Sivyer, D. B.: Environmental controls on phytoplankton community composition in the Thames plume, U.K., J. Sea Res., 60, 246254, doi:10.1016/j.seares.2008.09.003, 2008.

Winkler, L.: Die Bestimmung des in Wasser Gelösten Sauerstoffes, Ber. Dtsch. Chem. Ges., 21, 2843-2855, 1888. 